\section{Extrahepatic manifestations of hepatitis C}

We read with interest the article on extrahepatic manifestations of hepatitis C virus by Samuel and Rees. ${ }^{1}$ We report a dermatological manifestation of hepatitis $\mathrm{C}$, which the authors have not mentioned.

A 38-year-old man with hepatitis C was admitted with upper gastrointestinal bleed. He was found to have oesophageal varices that were banded. He developed a tender purpuric rash with ulceration on his lower limbs. There were no other associated symptoms. A clinical diagnosis of cryoglobulinaemia was considered. Vasculitic screen was negative.

Samples were tested for the presence of cryoglobulins using standard laboratory procedures comparing plasma and serum samples kept at $37^{\circ} \mathrm{C}$, with those then cooled and incubated at $4^{\circ} \mathrm{C}$ to demonstrate cryoprecipitation. Initial examination showed no visible precipitate and no cyroglobulin on protein electrophoresis. Because of the strong clinical suspicion that the patient had cryoglobulinaemia, the laboratory testing was repeated with a larger sample, observing strict adherence to the protocol, ensuring that the samples were rigorously maintained at $37^{\circ} \mathrm{C}$ at all stages until analysis. A visible precipitate was seen in EDTA plasma sample at $4^{\circ} \mathrm{C}$, which was confirmed as cryofibrinogen (CF) on immunofixation. No bands were seen in the $4^{\circ} \mathrm{C}$ serum sample. Skin biopsy showed dermal fibrosis. The rash improved when the patient was kept warm and he was referred for treatment of hepatitis C.

Cryofibrinogenaemia refers to a cryoprecipitate in plasma and was first described by Korst and
Kratochvil in 1955. CF is a cold insoluble complex of fibrin, fibrinogen, fibrin split products with albumin, fibronectin (cold-insoluble globulin), factor VIII, immunoglobulins and plasma proteins. $^{2}$

CF precipitates in plasma cooled to $4^{\circ} \mathrm{C}$ and redissolves on warming to $37^{\circ} \mathrm{C}$. CF is consumed in the clotting process and thus does not precipitate in cooled serum. CF can be essential (primary) or secondary to a variety of diseases including carcinoma, acute infections, inflammatory process, collagen vascular or thromboembolic disease and other miscellaneous conditions including chronic lung disease, myocardial infarction and hypothyroidism.

$\mathrm{CF}$ is often asymptomatic. Clinical signs include ischaemic painful ulcers, purpura, livedo reticularis, ecchymosis, perniosis of the extremities, gangrene and systemic manifestations of arthralgias, nephritic syndrome, multineuritis, fever and thrombosis. Sepsis resulting from secondary infection of gangrenous cutaneous tissue can cause death. ${ }^{3}$ Skin biopsy usually shows leucocytoclastic vasculitis and necrosis of dermis and epidermis although plugging of superficial and deep vessels with periodic acid-Schiff (PAS) positive thrombi is more specific.

The prevalence of CF is unknown but may be present in up to $3 \%$ of healthy individuals and has been demonstrated in nearly a third of patients screened on the basis of recognised symptoms as described above. CF may exist in isolation or in conjunction with cryoglobulinaemia. Between $70 \%$ and $100 \%$ of patients with mixed cryoglobulinaemia can test positive for hepatitis C. ${ }^{3}$ Low concentrations of mixed cryoglobulins are found in about $50 \%$ of patients with hepatitis $\mathrm{C}$ although only a minority are symptomatic.
However, in one study of 30 patients with isolated CF, only one was diagnosed with hepatitis $\mathrm{C}$ and another study of 61 patients with CF showed hepatitis $\mathrm{C}$ in only two patients, both of whom had combined $\mathrm{CF}$ and cryoglobulinaemia. ${ }^{24}$

This diagnosis of CF is often missed. If a serum sample is negative for cryoglobulins in a patient with hepatitis $\mathrm{C}$ who has presented with a vasculitic skin rash, a repeat serum sample with strict adherence to protocol should be sent to confirm a diagnosis of CF.

\section{Sanjay Gupta, ${ }^{1}$ Nadeem Tehami, ${ }^{1}$ Anne Tarn ${ }^{2}$ \\ ${ }^{1}$ Department of Gastroenterology, Croydon University Hospital, Croydon, UK \\ ${ }^{2}$ Department of Clinical Pathology, Croydon \\ University Hospital, Croydon, UK}

Correspondence to Dr Sanjay Gupta, Department of Gastroenterology, Croydon University Hospital, 530 London Road Croydon Surrey, Croydon, Surrey CR7 7YE, UK; san1gupta@hotmail.com

Contributors All authors have contributed to the management of this patient and in writing the manuscript.

Competing interests None.

Patient consent Obtained.

Provenance and peer review Not commissioned; internally peer reviewed.

To cite Gupta S, Tehami N, Tarn A. Frontline Gastroenterology 2014;5:224.

Received 5 October 2013

Accepted 7 October 2013

Published Online First 4 November 2013

\section{REFERENCES}

1 Samuel DG, Rees IW. Extrahepatic manifestations of hepatitis $\mathrm{C}$ virus (HCV). Frontline Gastroenterol 2013;4:249-54.

2 Blain H, Cacoub P, Musset L, et al. Cryofibrinogenemia: a study of 49 patients. Clin Exp Immunol 2000;120:253-60.

3 Ferri C, Zignego AL, Pileri SA. Cryoglobulins. J Clin Path 2002;55:4-13.

4 Belizna CC, Tron F, Joly P, et al. Outcome of essential cryofibrinogenemia in a series of 61 patients. Rheumatology $2008 ; 47: 205-7$. 